\title{
STRATEGY AND PORTFOLIO MANAGEMENT ASPECTS OF INTEGRATED BUSINESS PLANNING
}

\author{
Jurečka, P.
}

With ongoing globalization and the resulting growing competitiveness on most markets, companies are under constant pressure to increase the effectiveness and efficiencies of their operations. The focus of this paper is placed on one of the core business management processes - on planning, namely on Sales and Operations Planning (S\&OP) and its latest development stage, nowadays often recognized under the term Integrated Business Planning (IBP). The author's experience from leading the global implementation of IBP in a multinational chemical company is reflected in the proposition of how IBP can serve as an effective tool for execution of business strategy. The article further illustrates how different generic strategies and product portfolio models of the companies impact the set-up of an IBP process. As the IBP concept is applicable for almost all businesses and markets, it can be used broadly as an effective tool for facing the challenges of economic and financial crisis.

JEL Classification: M11, G17, L2

Keywords: portfolio management; integrated business planning

\section{Introduction}

Throughout the past decades, challenges brought by ongoing globalization of the economy and rising competitive pressures forced companies to abandon the traditional view of independent and often poorly aligned planning processes, executed separately by different business functions. Although the first concepts of structured production planning appeared as early as in the beginning of 1960s, when Joseph Orlicky studied Toyota's Manufacturing Program and developed a Material Requirements Planning (MRP) and later MRP II ${ }^{1}$ (Orlicky, 1975), it was the concept of S\&OP that came out as a first significant step forward trying to align planning activities across multiple business functions. Over the last 30 years, S\&OP has gradually evolved into a standard industry practice and reshaped its content and focus from predominantly production planning to a company-wide management process, recognized today more and more often under the term Integrated Business Planning (IBP).

1 Bringing also master scheduling, rough-cut capacity planning, capacity requirements planning and other concepts to classical MRP.
According to consultants from Oliver Wight ${ }^{2}$, a properly implemented IBP process routinely reviews the current and projected business performance starting with the review of strategy and portfolio changes, updated customer demand, required supply resources and resulting financial implications. The traditional view on S\&OP, as on the process merely balancing supply and demand, is thus long obsolete. Oliver Wight also defines several points that differentiate IBP from traditional S\&OP, with inclusion of strategic planning and more robust product and portfolio review put at forefront. ${ }^{3}$ Aberdeen Group researchers further state that "the key difference between traditional S\&OP and IBP is that IBP involves extensive collaboration between the various roles of the organization and enables the unification of business goals and strategies rather than just being a functional supply chain process" (Aberdeen Group, 2008, p. 4). As further noted by Palmatier and Crum, "focus of attention on S\&OP has been shifting towards a better understanding of the external environment as well as ensuring the alignment and synchronization among the internal functions

2 IBP/S\&OP: An executive level synopsis, Oliver Wight white paper series, http://www.oliverwight-americas.com

3 Adopted from Oliver Wight presentation on Integrated Business Planning Summit, IE Group, Zurich, March 2011. 
Figure 1: Strategy execution according to Kaplan and Norton

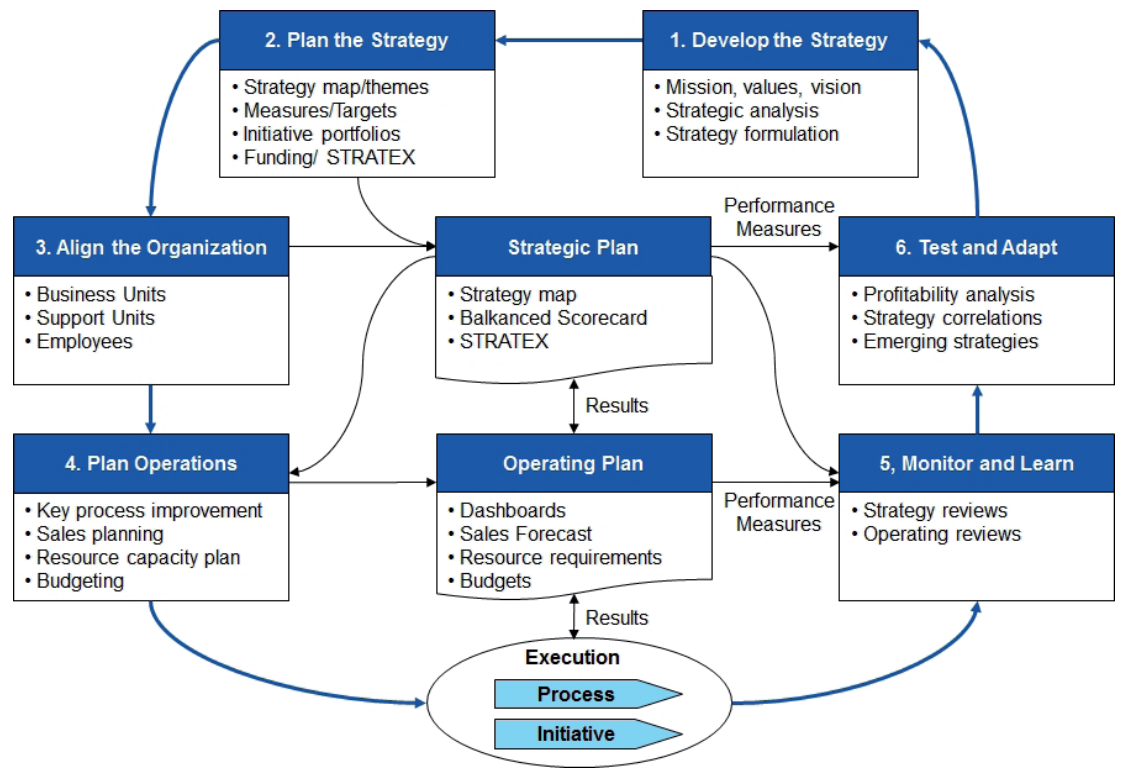

Source: Kaplan and Norton (2008), p. 8.

of the company" (Palmatier and Crum, 2010, p. 3). They further emphasize that the shift of S\&OP toward strategic management as being a key driver in the transition to IBP. To sum-up, structured inclusion of strategic initiatives into operational management forms one of the key prerequisites of shifting from traditional S\&OP into the state of the art concept of IBP. The following chapters analyze, in more detail, three relevant aspects of this shift from the perspective of IBP process set-up - reflection of strategy execution, encounter of generic competitive strategy and inclusion of portfolio development into operational planning and decision-making processes.

\section{IBP as a Tool of Strategy Execution}

In past decades, lots of improvements have been achieved in the field of development of strategy execution tools. Balanced scorecard has become probably the leading approach towards comprehensive management of an organization's performance, followed by systems based on the management of quality (Baldrige Criteria, TQM, six sigma, European foundation for Quality Management, etc.) or financial management (economic value added) (Lawson, Desroches and Hatch, 2008).

However, despite the existence of a myriad of strategy development and implementation tools, organizations are still often failing in successful execution of their strategies. According to Kaplan and Norton, strategy execution was placed in $1^{\text {st }}$ position in a comprehensive global survey on top-executives' priorities. Another study that they conducted about the state of strategy execution revealed, that ca. 40 percent of reviewed organizations still did not have formal systems to help them execute their strategies; over 70 percent reported average or below average performance of their strategies (Kaplan and Norton, 2008).

As a response to issues identified in the surveys mentioned above, Kaplan and Norton proposed a comprehensive and integrated management system that links strategy formulation and planning with operational execution as outlined in Figure 1. They claim that companies can benefit from taking this approach to linking strategy and operations through implementation of the described close-loop management system. The main drawback of such a system is that in most of the cases, implementation of such an extensive approach towards strategy execution would require the employees of the company to adopt and manage relatively a complex set of initiatives on the top of their current responsibilities. As a result, strategy implementation as a whole might hit resources constraints as well as change management-related hurdles.

Subsequent to the author's experience leading a world-wide implementation of the IBP concept within a major global player in the chemical industry, I suggest that failing to successfully implement the business strategy may be often grounded in insufficient integration, collaboration, communication and incentive setting amongst different business units in the "strategy-to-operations" cycle. The underlying reason for this phenomenon may be the lack of integration and structured cooperation amongst different business functions. 
As a practical example, let us use the missing alignment between multiple IT systems and tools, which are used to support the planning and reporting processes of Sales, Marketing, R\&D, Finance or Operations. Insufficient gap reconciliation between these systems and lack of understanding of the differences between the outcomes of independent planning processes result in inefficiencies in decision making and "surprises" for management. For example, Marketing, with a strategic mid-to-long term horizon, commonly ends up isolated from the comprehensive feedback from Sales on how markets really react to their proposed strategic initiatives. Moreover, Finance - with their strong value orientation - often focuses on the fulfillment of bottom line commitment defined in targets or budgets, with limited interest in the real sales volumes mix that is on the other hand crucial for Operations - Production and Distribution. The communication silos are not uncommon and incentives across the organization not being sufficiently aligned towards common targets. Each stakeholder of the planning process is not truly motivated for any deeper cooperation with the rest of the organization.

The question then is, how to set an effective approach towards strategy execution, one that would minimally interfere with current "daily" activities of the firm and tasks of the employees. In other words, how to integrate strategy execution into existing core management processes so that it becomes an integral part of business operations instead of being the one-off action that is being repeated once in a while when the strategy is reviewed. The concept of Integrated Business Planning provides the answer to the abovementioned questions.

As IBP is rather a business term without an exact definition, the author defines the following three main aspects that could be summarized as key characteristics of IBP or advanced S\&OP.

\section{IBP as a Key Platform for Operational Management of the Company}

IBP should be understood as a key process for operational management of the company. It should not complement, but replace the multiple planning processes that are often running in the business organizations in parallel. Furthermore, it should not be understood as only "planning", but mainly as a management "decision-making" process. The question of ownership should no longer focus on which individual business function should dominate the process, but rather on how to orchestrate the efforts of all functions into a single integrated process. These go hand in hand with alignment of incentives and individual target setting.

\section{IBP as a Structured Gap Management Process}

Content wise, the IBP process should be established so that it gradually identifies and manages different types of gaps.
These can be the gaps between various sales demand scenarios, between given budgets or targets and the latest forecasts, between different planning horizons and planning methods applied by individual business functions or between the level of detail and master-data structure amongst various planning systems. Throughout multiple gap reconciliation rounds within the monthly planning cycle, the organization should develop an integrated "one-number" sales demand forecast. This should reflect the bottom-up customer view of Sales balanced out with the top-down strategic view of Marketing. Furthermore, it should be reviewed from a feasibility perspective by Supply Chain and from a financial value perspective by Finance. On the top, this base case forecast should be accompanied with various sales scenarios reflecting different alternatives of underlying assumptions for further business opportunities and risks.

\section{IBP as a Linkage Between a Company's Strategy and Operations}

Alignment of different planning processes across the organization and structured management of the gaps between different plans should result in a consensus between top-down strategy execution and direct bottom up feedback from the marketplace. This approach can be implemented into the planning philosophy of the firm and thus serve as a constant and sustainable way of executing strategy and monitoring of its fulfillment.

Furthermore, as IBP is aiming primarily for improvements of one of the core management functions - planning, it can be implemented into the already existing process structure in the firm. Thus, contrary to some complex strategy implementation systems, it can serve as a relatively easy to achieve, efficient and sustainable way of linking strategy with operations.

The following two sections analyze, in more detail, how various generic strategies and portfolio models of the firm should be reflected in the set-up of an IBP process from the perspective of its owner or key decision-making power and related structure of key performance management indicators. Set-up of an Integrated Business Planning Process With Respect to Company's Strategy

One of the key factors that should be taken into account when deciding about optimal set-up of an IBP process in the firm is the general strategic focus of the company. Porter in his classic work Competitive Strategies identifies three main strategic options open to any organization that wishes to achieve a sustainable competitive advantage as displayed on the Figure 2. Adopting Porter's generic strategy view, three basic IBP set-ups can be derived based on the following key strategic directions of the company: 
Table 1: IBP ownership based on key strategic focus

\begin{tabular}{|c|c|c|c|}
\hline $\begin{array}{l}\text { Generic } \\
\text { strategy }\end{array}$ & Focus & $\begin{array}{l}\text { Leading } \\
\text { business } \\
\text { function }\end{array}$ & Key Performance Indicators \\
\hline $\begin{array}{l}\text { Cost } \\
\text { Leadership }\end{array}$ & $\begin{array}{l}\text { - One number principle for supply } \\
\text { - Volume } \\
\text { - } \text { Inventory minimization }\end{array}$ & $\begin{array}{l}\text { - Supply Chain/ } \\
\text { Operations } \\
\text { - Finance }\end{array}$ & $\begin{array}{l}\text { - Forecast accuracy } \\
\text { - Redution of forecast bias } \\
\text { - Inventory turns } \\
\text { - Asset ustilization }\end{array}$ \\
\hline $\begin{array}{l}\text { Focus on } \\
\text { customer } \\
\text { relations }\end{array}$ & $\begin{array}{l}\text { - Sales planning } \\
\text { - Impact of promotions } \\
\text { - Customer segmentation } \\
\text { - Risk and opportunities management } \\
\text { - Revenue growth }\end{array}$ & $\begin{array}{l}\text { - Sales } \\
\text { - Supply Chain/ } \\
\text { Operations }\end{array}$ & $\begin{array}{l}\text { - Customer retention } \\
\text { - Customer revenue/ profitability } \\
\text { - Inventory turns } \\
\text { - Delivery reliability }\end{array}$ \\
\hline $\begin{array}{l}\text { Product/ } \\
\text { Service } \\
\text { Differentiation }\end{array}$ & $\begin{array}{l}\text { - Scenario planning } \\
\text { - Product development } \\
\text { - Portfolio management } \\
\text { - Risk and opportunities management } \\
\text { - Profit growth }\end{array}$ & - Marketing & $\begin{array}{l}\text { - Profitability and revenue growth from } \\
\text { new products } \\
\text { - Brand value and health } \\
\text { - Time-to-market } \\
\text { - Inventory obsolence }\end{array}$ \\
\hline
\end{tabular}

Source: Author

- Cost leadership

- Product differentiation

- Customer (relationship) focus.

Different IBP set-ups reflecting the above mentioned strategies vary from each other in their functional ownership and emphasis on key focal points as well as in performance measures that should be applied to steer them within corporate performance management system.

Figure 2: Porter's generic strategies

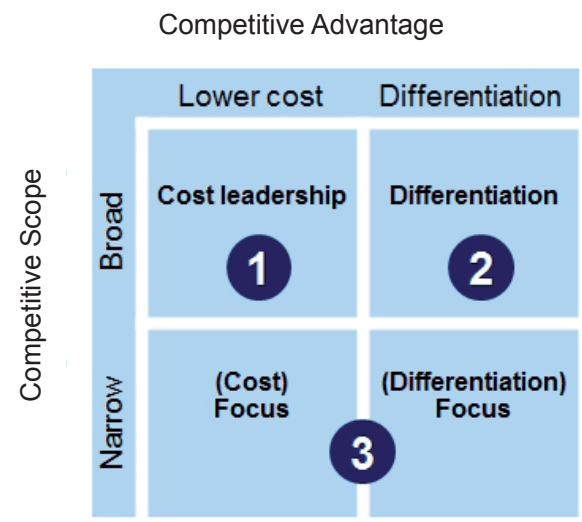

Source: adopted from Porter (1998).

\section{Cost Leadership}

For businesses that follow cost leadership as a strategy, managing supply plays a major role and the objective of the company is to supply the demand at lowest costs. This corresponds more to the traditional approach, where Supply
Chain had the dominant role in the decision making within the S\&OP process. The priorities in planning are set to eliminate the forecasting bias and improve forecast accuracy. Other critical success factors include discipline in execution and control of operations, elimination of waste, continuous improvement and reduction of layers in the organization. A single set of planning numbers in such an environment represents an important prerequisite to achieve effectiveness and efficiencies. Executive leadership in this process is in the hands of Operations and possibly Finance. The main key performance indicators complementing forecast accuracy are focused on customer service, assets utilization and costs of inventories.

\section{Product differentiation}

For a company operating in a business environment where the strategic focus is product differentiation, the key role in an IBP process is held by the Strategic Marketing, Product Management or Research \& Development functions. Support from Sales, Finance and Supply Chain is important but secondary. Decisions being made within the IBP process are focused on volume and margin growth and understanding further opportunities and risks. Scenario planning consisting of a range of planning figures is thus more common than the "one number principle". Further emphasis is put on strategic marketing, success of new product launches, filling of pipelines, minimization of obsolescence and portfolio management. Supply chain is expected to deliver high levels of responsiveness and flexibility due to the presence of higher forecast uncertainty and generally lower forecast accuracy levels. Key performance indicators are focused primarily on customer service, profitability, brand health and market shares. 


\section{Focus on Customer Relations}

Customer Relationships are of strategic focus for businesses where it is believed that customer segmentation and tailor made products and services are critical to success. In such cases, Sales represented by key account managers with the main focus on revenue growth should be the key driver of an IBP process, with the strong support of Marketing, Finance and Supply Chain. Similar to the previous case with product differentiation, understanding of business risks and opportunities is important in order to derive and manage various planning scenarios, rather than focusing on one set of numbers. Emphasis is further put on promotional activities and timely introduction of product line extensions. High levels of customer service and supply chain responsiveness at minimum cost are standard expectations. Principal targets include customer retention, customer penetration, revenue and profit by customer/channel or on-time product deliveries. Sales, as a business function, plays a critical role in executing the planning process in this situation.

Understanding the general strategic focus of the company is critical before embarking on IBP implementation. Getting this clarity will prevent the adoption of a "one-size-fits-all" concept where, by default, the strategy is misrepresented by operational excellence. Especially for businesses utilizing customer focus or product/service differentiation as a main strategy, there may be a lack of motivation of commercial functions - such as Marketing or Sales - to spend their time and efforts to discuss volume and cost implication for value and margin driven businesses. Table 1 summarizes the key elements and characteristics of IBP for each of the generic strategies.

\section{Strategic Portfolio Management Translated into IBP}

As already mentioned, portfolio structure may have significant implications on how an IBP process is established. Inclusion of these aspects into monthly planning cycle represents one of the key defining factors of the IBP concept. Within this section, it is demonstrated how different strategic options represented by various portfolio models can be reflected in an IBP process and enable the company to effectively link its strategic focus with operations.

Generally, the future product portfolio of the company defining its revenue streams may consist of the following four segments:

- current product line(s)

- extensions and promos of current product line(s)

- products new to the company but known in the market

- products new to the company and market
Various combinations of these portfolio segments are further defining several main portfolio models that have different impact on the set-up of IBP. Understanding of how the expected future market and portfolio situation will differ from the present and past is a key prerequisite for managing change related to IBP implementation as well as consecutive translation of business strategy into its operations within the planning process.

\section{Portfolio Model 1 - Managing Current Portfolio}

An IBP process set-up in Portfolio Model 1 would follow the traditional S\&OP structure, focused primarily on balancing supply and demand. As planning will deal dominantly with standard products, the emphasis will be on forecast accuracy and a single number planning approach for supply. This model appears generally for businesses dealing with commodity-like products, e.g. basic chemicals, and the ideal strategy to be chosen for such cases is cost leadership. As discussed also in sub-chapter 3.1 of this article, the key role in planning should be held by Operations and Finance. This is the only portfolio model where classical S\&OP would be still sufficient.

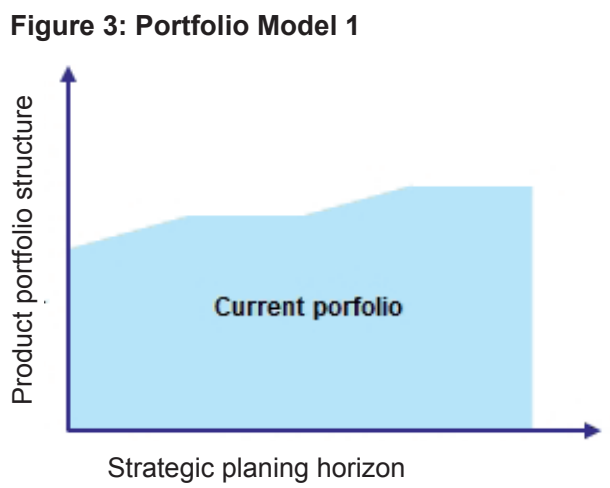

Source: Author

\section{Portfolio Model 2 - Growth Through Line Extensions and New Products}

The second portfolio model outlines the situation where future revenue streams are generated predominantly by line extensions and promos of the current product portfolio, but more importantly by the new products. Where the existing portfolio may follow a "cost leadership" strategy, the strategy chosen for the new product launches would need to be differentiation or superior customer relations focus in order to justify higher profit margins. Strategic portfolio management gains in importance within the IBP process, and the leadership within this process is shifted from Operations to commercial functions. 
Figure 4: Portfolio model 2

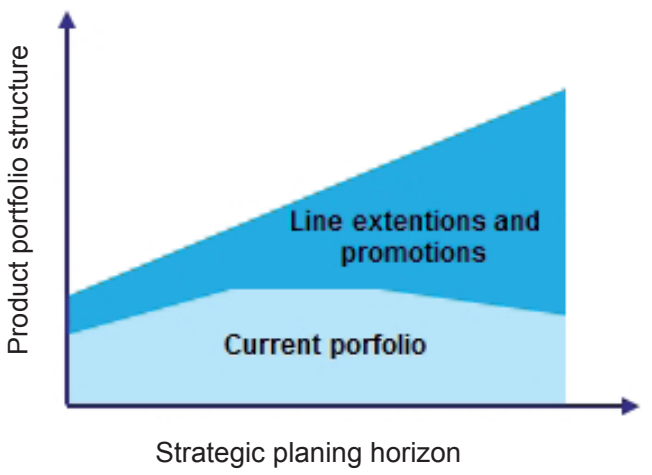

Source: Author

In case that the growth through the products new to the company is realized via the acquisition of a competitor having such products already in its portfolio or by the purchase of a respective patent, Finance will play a significant support role in the process. For the cases when the new product line results from in-house development, the R\&D or Product Development functions might be of significant importance.

\section{Portfolio Model 3 - Growth Through Brand New Product Lines}

The portfolio model where most of the expected future revenues are generated by products that are either new for the company or for the whole market represents the most challenging situation for the traditional view of S\&OP. Such situations are common in growing business segments that are driven by technology changes and very short product life-cycles. For these cases, strategic portfolio reviews represent one of the most important steps in the IBP process. The traditional S\&OP model of balancing demand and supply is of limited relevance to executives in this environment.

Figure 5: Portfolio model 3

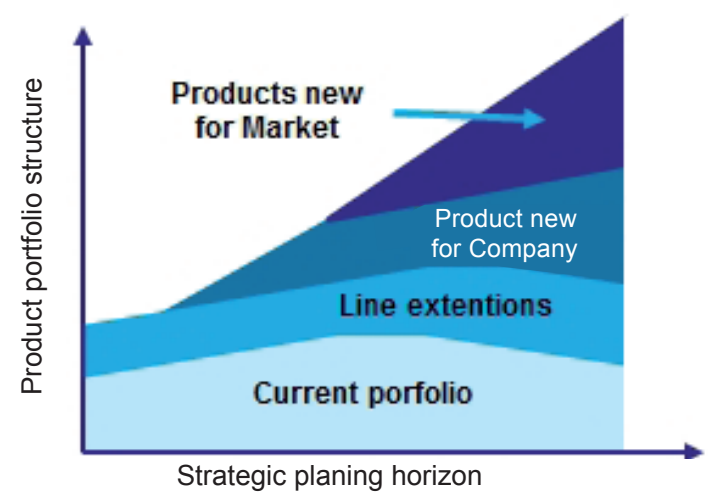

Source: Author
Uncertainty incorporated in planning for new product launches has to be managed by constant revaluation of various demand scenarios and of their impact on a company's profitability. Measurements such as 'time to market' and 'time to profit' are of key importance. Standard S\&OP software with its functionalities like statistical forecasting is of little value, as the possibilities for potential extrapolation of past demand figures are limited. Typical examples of industries following this portfolio model are high-tech manufacturers of mobile phones, electronics, computers and software. The typical generic strategy utilized for such industries is product or service differentiation.

If the business is following a portfolio model similar to Model 2 or 3 , spending time on only implementing a demand and supply process such as the traditional $\mathrm{S} \& \mathrm{OP}$ is ineffective. IBP with a strong focus on strategic product management represents the most appropriate approach to planning in such business environments. Proper coordination of different sales channels also plays a critical role in these two models.

\section{Conclusion}

Mastering the planning function becomes critical for coping with the fast changing business environment of a globalized economy. IBP, as the latest development stage of well-known $\mathrm{S} \& \mathrm{OP}$, has been proposed as an innovative approach to reaching operational excellence in planning. Understanding the business strategy of the company is an essential prerequisite to determining how the IBP process should be set. In the previous chapters, we discussed how different fundamental competitive strategies as well as various portfolio models impact the key focus, ownership and decision-making structure as well as performance measures of the planning process. A principal goal of the business is 'differentiation from competition' which leads to competitive advantage. Being able to recognize and apply different nuances and choices for establishment of effective planning process can be very helpful, whereas a one-size-fits-all universal checklist for IBP is not appropriate.

Having the generic strategy of the firm defined, IBP can also serve as an effective and relatively easy to implement tool for its execution. Via structured cooperation and integration across all key business functions, it creates the platform for effective linkage between a company's strategy and its operations.

\section{References}

Aberdeen Group (2008). Sales and Operations Planning Aligning business goals with supply chain tactics, Aberdeen Group research paper, www.aberdeen.com, June 2008.

Kaplan R.S., Norton D.P. (2008). The Execution Premium. Boston, MA: Harvard Business Press. 
Lawson, R., Desroches, D., Hatch, T. (2008). Scorecard

Author

Best Practices: Design, Implementation and Evaluation. Hoboken, NJ: John Wiley.

Ing. Peter Jurečka, M.A.

Orlicky, J. (1975). Material Requirements Planning: A New Way of Life in Production and Inventory Management. New York: McGraw Hill.

Palmatier, G.E., Crum, C. (2010). A Transition from Sales and Operations Planning to Integrated Business Planning, Oliver Wight whitepaper series - Informative guide on industry best practices, Oliver Wight Americas.

Porter, M. (1998). Competitive Strategy: Techniques for Analyzing Industries and Competitor. New York: Free Press.

Postgraduate student, Department of Business

Economics

Faculty of Business Administration University of Economics, Prague Winston Churchill Sq. 4, 13067 peter.jurecka@gmail.com 